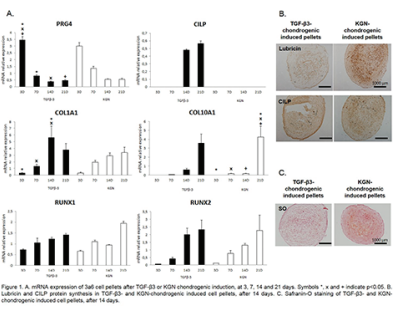

Results: The molecular analysis of KGN- and TGF- $\beta 3$-chondrogenic induced $3 \mathrm{a} 6$ pellets is depicted in figure $1 \mathrm{~A}$. For zonal markers expression, both conditions showed a significant downregulation in PRG4 with time, concomitant with an upregulation of CILP, for TGF- $\beta 3$ but not for KGNinduced cells. However, PRG4 and CILP were found on the protein level (Figure 1B) for both conditions. The studied zonal markers were found heterogeneously distributed for KGN-induced pellets (Figure 1C). This difference is also supported by proteoglycans SO staining, with an earlier formation of a more mature tissue for KGN- than TGF- $\beta 3$-induced pellets. No expression was found for the main hyaline-like cartilage collagen (COL2A1). RUNX1 was practically unaltered in both conditions. For hypertrophic markers, RUNX2 was upregulated at 14 days in TGF- $\beta 3$ - whilst, in KGN-induced cells its expression seems to be delayed, although no significant differences were found. In both conditions, COL10A1 was very low, until 21 days. COL1A1 presented a significant upregulation at 14 days for TGF- $\beta 3$ - whilst in KGN-induced cells expression was non-significant.

Conclusion: This is the first study to report the chondrogenic effect of kartogenin on $3 a 6$ immortalized human bone marrow MSCs line. On the molecular level, no significant differences were found between KGN- and TGF- $\beta 3$ chondroinduction, although transition into a hypertrophic phenotype seems to be delayed. On the protein level, zonal markers and proteoglycan synthesis were found improved by kartogenin after 14 days.

REFERENCE:

[1] Johnson K, et al. Science 2012, 11;336(6082):717-21.

Disclosure of Interests: carolina guiance-varela: None declared, Cristina Rodríguez-Pereira: None declared, Elena Fernandez-Burguera: None declared, Tamara Hermida Gómez: None declared, Noa Goyanes: None declared, Francisco J. Blanco Consultant for: AbbVie, Bioiberica, BMS, GSK, Grünenthal, Janssen, Lilly, Pfizer, Regeneron, Roche, Sanofi, TRB Chemedica, and UCB, joana magalhães: None declared DOI: 10.1136/annrheumdis-2019-eular.5526

\section{FRI0517 ANTI-CARBAMYLATED PROTEINS ANTIBODIES INDUCE OSTEOCLASTOGENESIS}

Laura Massaro ${ }^{1}$, Tania Colasanti ${ }^{1}$, Francesca Spinelli ${ }^{1}$, Fulvia Ceccarelli ${ }^{1}$, Riccardo Mancini ${ }^{1}$, Arbi Pecani ${ }^{1}$, Enrica Cipriano ${ }^{1}$, Carlo Perricone ${ }^{1}$, Francesca Miranda ${ }^{1}$, Simona Trugliaa ${ }^{1}$, Francesco Natalucci ${ }^{1}$, Martina Leopizzi ${ }^{2}$, Valeria DI Maio ${ }^{2}$, Carlo Della Rocca ${ }^{2}$, Cristiano Alessandri ${ }^{1}$, Guido Valesini ${ }^{1}$ Fabrizio Conti'. . Sapienza, University of Rome, Internal Medicine and Medical Specialties, Rome, Italy, ${ }^{2}$ Sapienza, University of Rome, Science and medicalsurgical Biotechnology, Rome, Italy

Background: Post-translational-modifications (PTMs) are implicated in the pathogenesis of autoimmune diseases, leading to the break of self-tolerance, generation of new autoantigens and production of autoantibodies. Anti-citrullinated-proteins antibodies (ACPA) play a key role in the pathogenesis of rheumatoid arthritis (RA) and many evidences showed that they are related to bone loss in RA. Osteoclasts are the primary targets of ACPA in the joint site, displaying citrullinated antigens on their surface. Carbamylation is another PTM generating the production of anti-carbamylated proteins antibodies (anti-CarP), recently proposed as a new biomarker for RA. Anti-CarP have been also studied in patients with systemic lupus erythematosus (SLE) with predominant joint involvement, showing a prevalence of $46.1 \%$. Moreover, in SLE patients these autoantibodies have been also associated to bone erosive damage. The pathogenic mechanism of these autoantibodies is not completely clarified so far.

Objectives: The aim of the present study was to investigate the possible pathogenic role of anti-CarP in the induction of osteoclastogenesis.

Methods: Peripheral blood mononuclear cells (PBMCs) were isolated from a buffy coat from healthy donors using a Ficoll Hypaque gradient. Cells were cultured for 14 days in $\alpha$-MEM complete medium, supplemented with $25 \mathrm{ng} / \mathrm{ml}$ of macrophage-colony-stimulating-factor (MCSF) and $30 \mathrm{ng} /$ $\mathrm{ml}$ of receptor activator of nuclear-factor-kappa-B-ligand (RANKL), for the differentiation of monocytes in osteoclasts. Simultaneously, PBMCs were co-cultured in presence of anti-carbamilated-vimentin autoantibodies (antiVim CarP) purified from sera of 3 patients with RA and 3 patients with SLE with a predominant joint involvement at $100 \mathrm{ng} / \mathrm{ml}$ and $1 \mu \mathrm{g} / \mathrm{ml}$. As control, intravenous immunoglobulin (IVIg) were used at the same concentrations. After 14 days, osteoclast differentiation was evaluated by staining cells for tartrate-resistant acid phosphatase (TRAP), using leukocyte acid phosphatase kit.

Results: Anti-VimCarP purified from RA patients at $100 \mathrm{ng} / \mathrm{ml}$ were able to increase the median number of osteoclasts per well significantly more than untreated and IVIg at $100 \mathrm{ng} / \mathrm{ml}$ and $1 \mu \mathrm{g} / \mathrm{ml} \quad(P=0.0008 ; P=0.0009$ and $P=0.0009$, respectively). The same results were observed treating cells with $1 \mu \mathrm{g} / \mathrm{ml}$ of anti-VimCarP from RA patients ( $P=0.0008, P=0.002$ and $P=0.002$, respectively). Similarly, anti-VimCarP purified from SLE patients at $100 \mathrm{ng} / \mathrm{ml}$ significantly increased the median number of osteoclasts than untreated and IVlg at $100 \mathrm{ng} / \mathrm{ml}$ and $1 \mu \mathrm{g} / \mathrm{ml} \quad(P=0.002$, $\mathrm{P}=0.004$ and $\mathrm{P}=0.003$, respectively). Analogously, we observed similar results co-culturing cells with $1 \mu \mathrm{g} / \mathrm{ml}$ of anti-VimCarP from SLE patients $(\mathrm{P}=0.002, \mathrm{P}=0.02$ and $\mathrm{P}=0.006$, respectively).

Conclusion: For the first time, we demonstrated that anti-Vim CarP purified from RA and SLE patients are able to induce osteoclastogenesis, suggesting their potential role as a biomarker of joint erosiveness in these autoimmune diseases.

Disclosure of Interests: : Laura Massaro: None declared, Tania Colasanti None declared, francesca spinelli: None declared, Fulvia Ceccarelli: None declared, Riccardo Mancini: None declared, Arbi Pecani: None declared, enrica cipriano: None declared, Carlo Perricone Speakers bureau: BMS Lilly, Celgene, Sanofi, Francesca Miranda: None declared, Simona Truglia: None declared, Francesco Natalucci: None declared, Martina Leopizzi: None declared, Valeria Di Maio: None declared, Carlo Della Rocca: None declared, cristiano alessandri: None declared, Guido Valesini: None declared, fabrizio conti: None declared

DOI: 10.1136/annrheumdis-2019-eular.6859

\begin{tabular}{l|l}
\hline FRI0518 & LONGITUDINAL EVALUATION OF SYNOVIAL \\
& FLUID AND SYNOVIAL FLUID MSC TRANSCRIPT \\
& CHANGES IN SUBJECTS UNDERGOING JOINT \\
& DISTRACTION
\end{tabular}

Thomas Baboolal ${ }^{1}$, Mylène Jansen ${ }^{2}$, Elena Jones ${ }^{1}$, Carla Sanjurjo-Rodríguez ${ }^{3}$ Tim Welting ${ }^{4}$, Pieter Emans ${ }^{4}$, Floris Lafeber ${ }^{2}$, Dennis Mcgonagle ${ }^{1}$, Simon Mastbergen ${ }^{2} .^{1}$ University of Leeds, Leeds Institute of Rheumatic and Musculoskeletal Medicine, University of Leeds, Leeds, United Kingdom; ${ }^{2}$ University Medical Center Utrecht, Rheumatology and Clinical Immunology, Utrecht, Netherlands; ${ }^{3}$ Universidade da Coruña, Coruña, Spain; ${ }^{4}$ Maastricht University Medical Center, Department of Orthopedic Surgery, Maastricht, Netherlands

Background: In relatively young patients with end-stage knee osteoarthritis $(\mathrm{OA})$, total knee arthroplasty (TKA) comes with the risk of future revision surgery [1]. Knee joint distraction (KJD) is a joint preserving surgical technique, which has been shown to provide clinical and structural improvement for over five years $[2,3]$ and postpones the need for TKA. The underlying mechanism however, is largely unknown. It is anticipated that an alteration of joint homeostasis including synovial fluid resident mesenchymal stem cells (MSCs), and their access to the superficial arthritic surface, is key to the regenerative process seen with KJD.

Objectives: To evaluate the longitudinal changes in synovial fluid MSC numbers and their gene expression profile upon KJD.

Methods: Patients with established symptomatic radiographic knee OA undergoing KJD gave written informed consent to participate. Synovial fluid (SF) was sampled at baseline (before distraction; pre), at midpoint (after 3 weeks; during) and at endpoint of distraction (6 weeks; post). MSCs were isolated and Colony Forming Units (CFU; MSCs) were determined. Moreover, gene expression profiles in isolated synovial fluid (SF) MSCs was determined by Realtime PCR for genes known to be involved in joint morphogenesis, cartilage homeostasis and $\mathrm{OA}$, which included: Aggrecan (ACAN), Growth/Differentiation Factor 5 (GDF5), Gremlin 1 (Grem1), Parathyroid Hormone 1 receptor (PTH1R), Discoidin Domain receptor 2 (DDR2), A disintegrin and metalloproteinase with thrombospondin motifs 4, Aggrecanase 1 (ADAMTS4), SRY-related proteins 9 (SOX9), Fatty acid binding protein 4 (FAB4), and Parathyroid hormone related protein (PTHLH). All data were normalized to HPRT (2$\Delta \mathrm{Ct})$. 

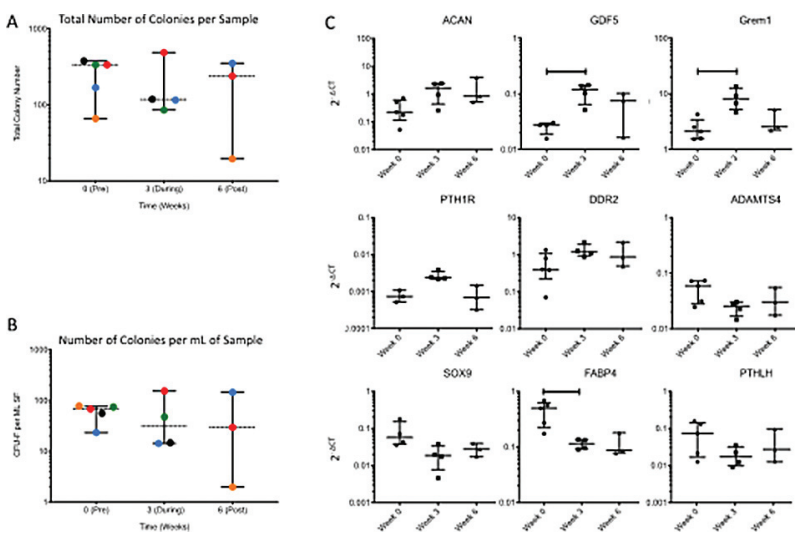

Results: Participants had a mean age $47 \pm 9$ yrs and 6 out 7 (86\%) were female. All had $\mathrm{KL}$ grade $\geq 2$ with substantial knee pain at baseline. Enough SF $(>500 \mu \mathrm{ll})$ could be obtained from $n=7$ at baseline, $n=4$ at midpoint, and $\mathrm{n}=3$ at endpoint of distraction. For the first time in this same group, we show how MSC number initially decline upon KJD (figure $1 \mathrm{~A}-\mathrm{B})$ as seen previously in our animal study [4]. Also, MSCs present in the SF showed changes in their gene expression profile upon KJD, most clearly observed during the treatment (3 weeks; figure 1C). GDF5 and Grem1 presented with a statistically significant increased expression $(p<0.05)$ during treatment while FAB4 expression was decreased. ACAN, PTH1R, and DDR expression had the tendency to increase over time. ADAMTS4, SOX9 and PTHLH expression showed a trend to decrease over time.

Conclusion: This explorative study provides for the first-time data on changes in SF MSC number and their gene expression profiles upon knee joint distraction. As such, first clues are provided for the involvement of MSCs in the regenerative process induced by joint distraction for end-stage knee OA. The fall in SF MSCs number during distraction suggests adhesion to the arthritic surfaces in the KJD environment as found in our previous work in canine KJD [4]. Further studies are necessary to unravel the processes involved.

\section{REFERENCES:}

[1] SM Kurtz, et al. Clin Orthop Relat Res 2009, 467(10):2606-

[2] J-TAD van der Woude, et al. Cartilage 2017, 8(3):263-

[3] MP Jansen, et al. Osteoarthritis Cartilage. 2018; 26(12):1604-

[4] T Baboolol, et al. Ann Rheum Dis. 2016;75(5):908-

Acknowledgement: Funded by FOREUM and Dutch Arthritis Society.

Disclosure of Interests: Thomas Baboolal: None declared, Mylène Jansen: None declared, Elena Jones: None declared, Carla Sanjurjo-Rodríguez: None declared, Tim Welting: None declared, Pieter Emans: None declared, Floris Lafeber Shareholder of: ArthroSave, Grant/research support from: FOREUM; Dutch Arthritis Society, Dennis McGonagle Consultant for: Lilly, Novartis UCB, Speakers bureau: Lilly, Novartis UCB, Simon Mastbergen Grant/research support from: FOREUM; Dutch Arthritis Society DOI: 10.1136/annrheumdis-2019-eular.3001
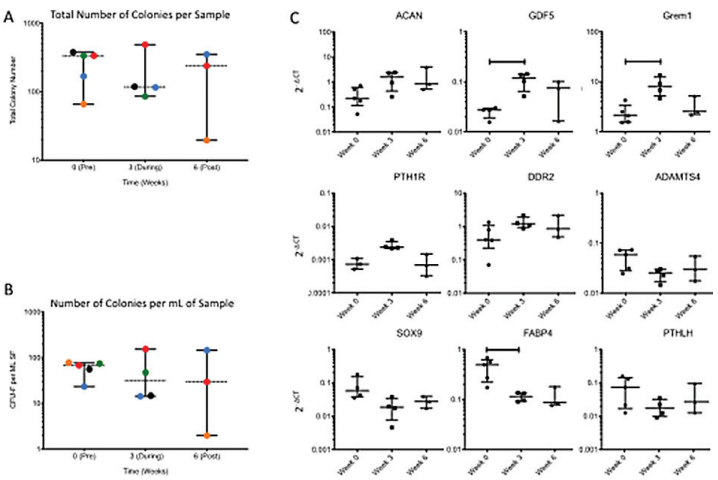

Figure 1. Changes in synovial fluid MSCs numbers and gene expressing profiles upon knee joint distraction. Bar indicates statistically significant changes $(p<0.05)$.

\section{FRI0519 \\ IDENTIFICATION OF CELLULAR TARGETS FOR ANTI-} CITRULLINATED PROTEIN ANTIBODIES (ACPAS)

Bence Réthi, Meng Sun, Alexandra Circiumaru, Akilan Krishnamurthy,

Heidi Wähämaa, Jimmy Ytterberg, Vivianne Malmström, Lars Klareskog,

Anca Catrina. Karolinska Institutet and Karolinska University Hospital, Department of Medicine, Solna, Stockholm, Sweden

Background: Autoantibodies against citrullinated proteins (ACPAs) have been suggested to play important roles in RA pathogenesis (1-3).

Objectives: In order to further dissect how ACPAs influence bone homeostasis and inflammation in the joints we analyzed the binding of different ACPA clones to target antigens produced by synovial fibroblasts, osteoclasts (OCs) or neutrophil granulocytes.

Methods: Fibroblasts were isolated from synovial tissue of RA patients by enzymatic digestion. Monocytes and neutrophil granulocytes were isolated from the peripheral blood of healthy individuals. Osteoclasts were generated from monocyte-derived dendritic cells in the presence of M-CSF and RANK-L. Polyclonal ACPAs were purified from pooled serum samples of RA patients using protein $G$ and Cyclic Citrullinated Peptide-based affinity chromatography. Monoclonal ACPAs were isolated from synovial plasma cells of RA patients, as described (4). Protein citrullination was analyzed with mass spectrometry. ACPA binding was analyzed using confocal microscopy and flow cytometry. Neutrophil extracellular trap (NET) formation was monitored using IncuCyte and confocal microscopy.

Results: Synovial fibroblasts expressed surface antigens to the ACPA clone 1325:01B09 following exposure to cellular stress (serum withdrawal) or IL-8 stimulation. Osteoclasts and their precursors were characterized by steady state protein citrullination and these cells were recognized by another distinct ACPA clone 1325:04C03. Using mass spectrometry, we detected citrullinated actin and vimentin in developing OCs. Interestingly, both proteins were present on the cell surface, showing a partial colocalization with the cell-bound 1325:04C03 antibodies.

Neutrophil granulocytes exposed a large amount of citrullinated targets for both 1325:04C03 and 1325:01B09 as well as for polyclonal ACPAs in neutrophil extracellular traps (NETs), irrespectively of the stimulus that triggered NETosis. Activation of the cells by $\mathrm{Ca} 2+$ ionophores triggered a rapid NETosis and cellular disintegration, in parallel with a profound reactivity of all tested ACPAs with both intracellular or surface antigens. Other activation signals, e.g. PMA, nigericin, zymosan or IL-8 did not induce protein citrullination in the cells, even in conditions where citrullinated proteins were detected in NETs.

Conclusion: Distinct monoclonal ACPAs target different cell types, suggesting unique pathological roles for individual ACPA clones. OCs might be among the earliest ACPA targets due to their physiological protein citrullination. Fibroblasts, on the contrary, acquired ACPA sensitivity only following cellular stress signals. Intact neutrophils were not targeted by ACPAs, whereas damaged cells and the extruded NET products might be important sources of citrullinated antigens that form immune complexes with ACPAs.

\section{REFERENCES:}

[1] Harre, U. et al. J Clin Invest (2012)

[2] Krishnamurthy, A. et al. Ann Rheum Dis (2016)

[3] Wigerblad, G. et al. Ann Rheum Dis (2016)

[4] Steen, J. et al. Arthritis Rheumatol (2018)

Disclosure of Interests: Bence Réthi: None declared, Meng Sun Grant/ research support from: Yes, but not for presented project., Alexandra Circiumaru: None declared, Akilan Krishnamurthy: None declared, Heidi Wähämaa: None declared, Jimmy Ytterberg Employee of: Currently employed by Sobi, Stockholm, Sweden. Earlier, during his contribution in the presented study he was $100 \%$ employed by the Karolinska Institutet., Vivianne Malmström Grant/research support from: Yes, but not for the presented study., Lars Klareskog Grant/research support from: Yes, but not for the presented study., Anca Catrina Grant/research support from: Yes, but not for the presented study.

DOI: 10.1136/annrheumdis-2019-eular.4179 